\title{
Diagnosis and treatment of lipodystrophy: a step-by-step approach
}

\author{
D. Araújo-Vilar ${ }^{1}$ D $\cdot$ F. Santini ${ }^{2}$
}

Received: 6 December 2017 / Accepted: 9 April 2018 / Published online: 27 April 2018

(c) The Author(s) 2018

\begin{abstract}
Aim Lipodystrophy syndromes are rare heterogeneous disorders characterized by deficiency of adipose tissue, usually a decrease in leptin levels and, frequently, severe metabolic abnormalities including diabetes mellitus and dyslipidemia.

Purpose To describe the clinical presentation of known types of lipodystrophy, and suggest specific steps to recognize, diagnose and treat lipodystrophy in the clinical setting.

Methods Based on literature and in our own experience, we propose a stepwise approach for diagnosis of the different subtypes of rare lipodystrophy syndromes, describing its more frequent co-morbidities and establishing the therapeutical approach.

Results Lipodystrophy is classified as genetic or acquired and by the distribution of fat loss, which can be generalized or partial. Genes associated with many congenital forms of lipodystrophy have been identified that may assist in diagnosis. Because of its rarity and heterogeneity, lipodystrophy may frequently be unrecognized or misdiagnosed, which is concerning because it is progressive and its complications are potentially life threatening. A basic diagnostic algorithm is proposed. Effective management of lipodystrophy includes lifestyle changes and aggressive, evidence-based treatment of comorbidities. Leptin replacement therapy (metreleptin) has been found to improve metabolic parameters in many patients with lipodystrophy. Metreleptin is approved in the United States as replacement therapy to treat the complications of leptin deficiency in patients with congenital or acquired generalized lipodystrophy and has been submitted for approval in Europe.

Conclusions Here, we describe the clinical presentation of known types of lipodystrophy, present an algorithm for differential diagnosis of lipodystrophy, and suggest specific steps to recognize and diagnose lipodystrophy in the clinical setting.
\end{abstract}

Keywords Diabetes $\cdot$ Dyslipidemia $\cdot$ Insulin resistance $\cdot$ Leptin replacement $\cdot$ Metreleptin

\section{Introduction}

Rare diseases are complex, chronic, often little-known conditions that can have debilitating health consequences and high morbidity and can impair quality of life. They are poorly understood by general practitioners and medical specialists alike, in part because of their low prevalence and frequent phenotypic heterogeneity. Lack of knowledge about rare disorders often leads to long delays in diagnosis and

D. Araújo-Vilar

david.araujo@usc.es

1 UETeM-Molecular Pathology Group, Institute of Biomedical Research (CIMUS), School of Medicine, University of Santiago de Compostela, Santiago de Compostela, Spain

2 Endocrinology Unit, Obesity Center, University Hospital of Pisa, Pisa, Italy sometimes to misdiagnosis, which can be greatly detrimental to patients.

Lipodystrophy syndromes, a collection of rare heterogeneous disorders characterized by a deficiency of adipose tissue without evidence of nutrition deprivation or a catabolic state, are no exception [1]. These disorders may be associated with a severe form of metabolic syndrome caused by abnormal deposition of fat that cannot be stored in appropriate subcutaneous depots [2]. Loss of adipose tissue frequently results in a decrease in leptin levels [3], which interferes with hunger-satiety signals and often leads to hyperphagia [4]. Surplus calories are stored as fat in liver and muscle tissue, resulting in insulin resistance, hypertriglyceridemia, and hepatic steatosis.

Excluding HIV-related lipodystrophy, the worldwide prevalence of lipodystrophy was recently estimated from searches of large electronic medical record databases to be 3.07 cases per million population [0.23 cases/million of 
generalized lipodystrophy (GLD) and 2.84 cases/million of partial lipodystrophy (PLD)]. Through literature searches, the prevalence of GLD and PLD was estimated to be 0.96 and 1.67 cases per million population, respectively [5].

The objective of this review was to establish a phased strategy allowing clinicians to attain a reasonably reliable diagnosis of the different lipodystrophy subtypes as well as to outline the therapeutic approach.

\section{Recognition and diagnosis of lipodystrophy}

Recognition of a lipodystrophy disorder is based on clinical history and physical examination that reveal a distinct body composition and metabolic state. Lipodystrophy is classified according to the manner of acquisition (genetic or acquired) and the distribution of adipose deficiency (generalized or partial). Thus, there are four major subtypes: congenital GLD (CGL), acquired GLD (AGL), familial PLD (FPLD), and acquired PLD (APL) (Table 1) [1].

Because of their rarity and heterogeneity, lipodystrophy disorders may frequently be unrecognized or misdiagnosed. Clinicians can differentiate lipodystrophy from other diseases and determine the appropriate subtype using the following steps.

\section{Step 1: Determination of whether the patient has lipodystrophy}

Because of its pervasive features, GLD represents a recognizable phenotype of lipodystrophy. Conversely, the presentation of PLD can be more subtle. PLD may be recognized, in part, by a characteristic pattern of fat loss, described in more detail later in this review $[4,6,7]$. Patients with lipodystrophy may present with the disease in childhood or as adults, and the onset may be sudden or insidious. With few exceptions [8], a major characteristic of lipodystrophy disorders is that fat loss never recovers.

Lipodystrophy should be suspected when a patient presents with a congenital deficiency of subcutaneous adipose tissue (SAT), progressive loss of SAT associated with autoimmune diseases, loss of SAT in limbs concurrent with the accumulation of fat in other body regions, or deficiency of SAT associated with other somatic abnormalities [9]. Additional physical features may include failure to thrive (in children), prominent muscles and veins, acanthosis nigricans, eruptive xanthomas, or cushingoid or acromegaloid appearance [1]. If the patient also has diabetes mellitus requiring high insulin doses, severe hypertriglyceridemia, nonalcoholic steatohepatitis, or polycystic ovarian syndrome (PCOS), lipodystrophy may be further indicated [9].

Diagnosis of lipodystrophy is based on clinical history, physical examination, and assessment of body composition, with laboratory findings useful in some cases. While no firm diagnostic criteria for lipodystrophy have been established based on skinfold measurements or imaging procedures such as dual-energy X-ray absorptiometry and magnetic resonance imaging, all of these evaluations can assist with diagnosis [6,10-13]. Although serum leptin levels in patients with lipodystrophy tend to be low (in absolute levels or relative to body mass index), no defined serum leptin level threshold can be used to rule out the diagnosis of lipodystrophy [1].

An algorithm for differential diagnosis of lipodystrophy subtypes is shown in Fig. 1. The differential diagnosis includes a range of disparate conditions $[9,14,15]$ such as the following:

- Severe weight loss due to anorexia nervosa, starvation, malnutrition, uncontrolled diabetes, hyperthyroidism, adrenal insufficiency, cancer cachexia, or severe chronic infection.

- Donohue syndrome (leprechaunism) and RabsonMendenhall syndrome, which are both recessive syndromes associated to variants in the INSR gene. Leprechaunism is the most severe disorder characterized by craniofacial abnormalities including elfin face, large, low-set ears, growth retardation, marked lack of adipose tissue, decreased muscle mass, hypertrichosis, pachyderma, acanthosis nigricans, virilization, and severe insulin resistance with paradoxical hypoglycemia. Death often occurs during early infancy. Children with Rabson-Mendenhall syndrome have a longer survival (15-20 years old) and present with coarse face with prognathism, dental crowding, short stature, thin non-lipoatrophic body type, severe acanthosis nigricans, phallic enlargement or clitoromegaly, paradoxical hypoglycemia, hyperinsulinemia, and diabetic ketoacidosis [16].

- Multiple symmetric lipomatosis.

- Cushing syndrome.

\section{Step 2: Evaluation of the extent of lipodystrophy}

Once the diagnosis of lipodystrophy is established, clinicians should investigate whether the disorder is generalized, partial, or localized. In generalized forms, total or near-total loss of subcutaneous fat can be observed over the entire body. In partial forms, fat loss affects large areas, particularly the limbs, but adipose tissue may accumulate in spared regions such as the face and neck in FPLD, while APL is 
Table 1 Classification of lipodystrophies [1, 17, 25-32, 49-58]

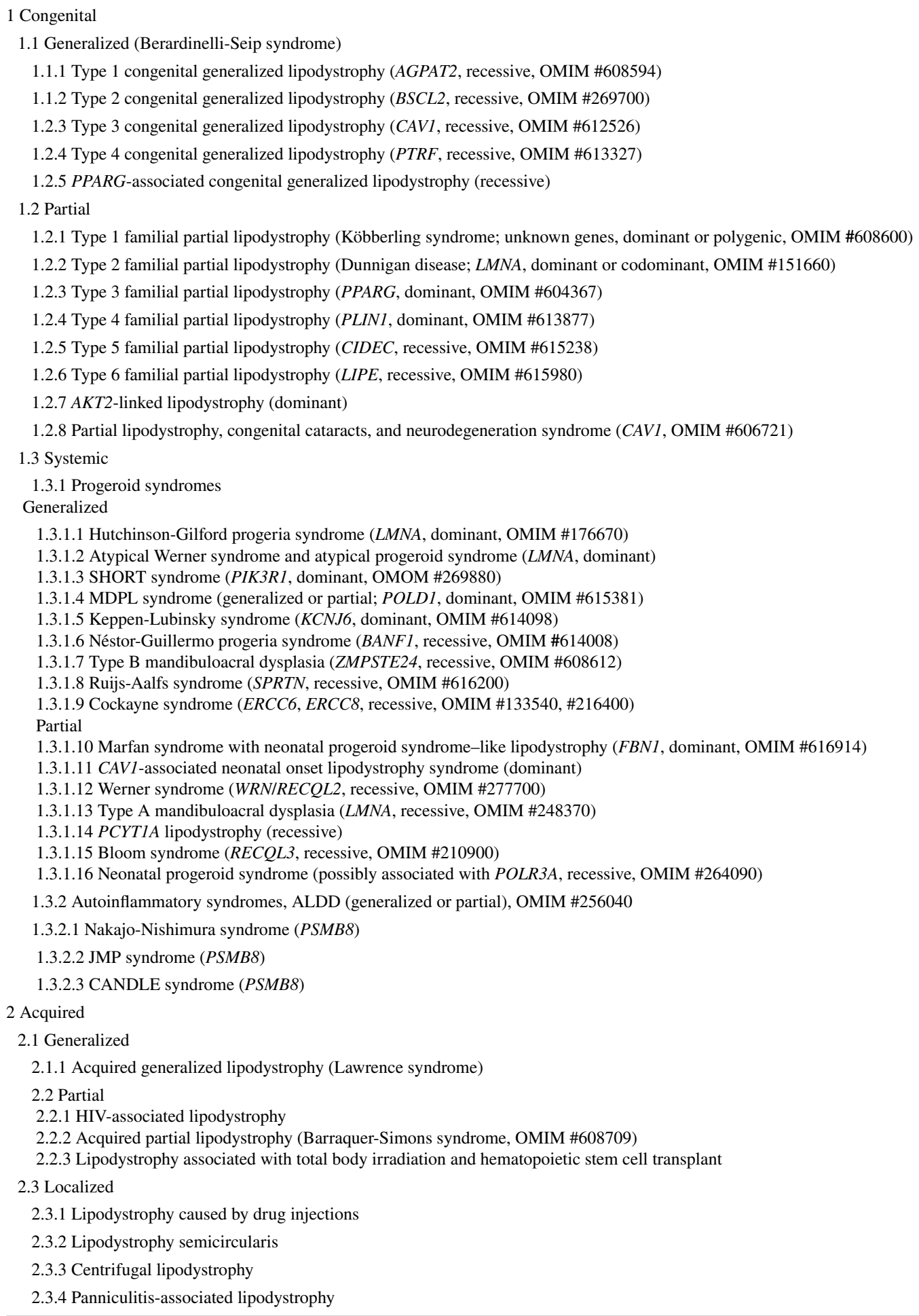

From: Online Mendelian Inheritance in Man (http://www.omim.org)

$A L D D$ autoinflammation, lipodystrophy, and dermatosis syndrome, CANDLE chronic atypical neutrophilic dermatosis with lipodystrophy and elevated temperature, $J M P$ joint contractures, muscle atrophy, microcytic anemia, and panniculitis-induced lipodystrophy, $M D P L$ mandibular hypoplasia, deafness, and progeroid features and lipodystrophy, OMIM Online Mendelian Inheritance in Man, SHORT short stature, hyperextensibility of joints, hernia, ocular depression, Rieger anomaly, and teething delay 


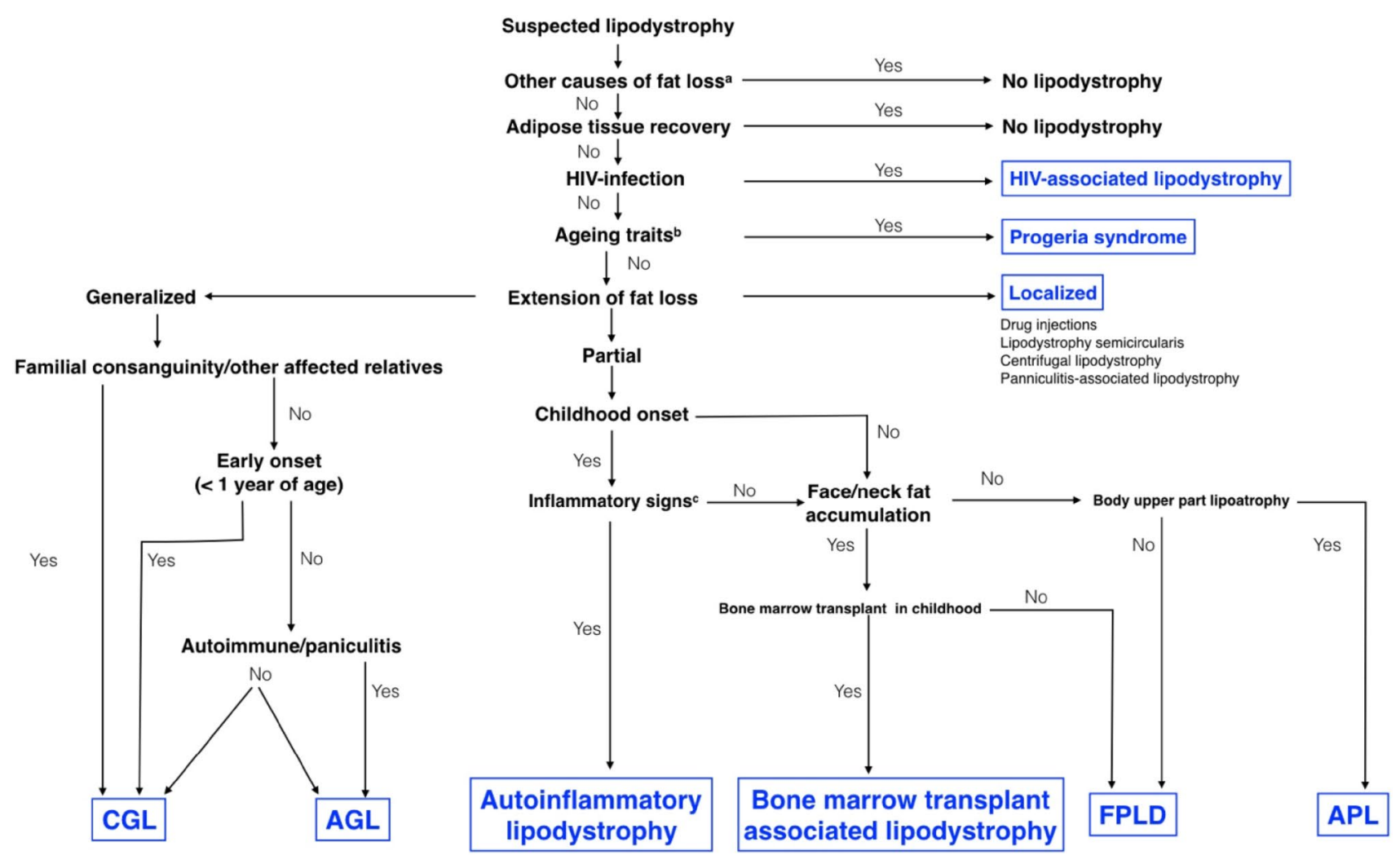

Fig. 1 A guide to diagnosing different subtypes of lipodystrophy. Diagnosis of lipodystrophy is largely based on physical examination and clinical history. When abnormal fat loss is observed, other diseases (a) causing a negative energy balance should first be excluded (malnutrition, anorexia nervosa, uncontrolled diabetes mellitus, thyrotoxicosis, adrenocortical insufficiency, cancer cachexia, and chronic infections). Recovery of adipose tissue also makes lipodystrophy unlikely. Patients with HIV receiving antiretroviral treatment often develop a syndrome characterized by peripheral lipoatrophy, trunk fat accumulation, and metabolic abnormalities, the pathogenesis of which remains not completely defined. Progeroid syndromes may be associated with lipodystrophy: Aging traits (b), such as short stature, alopecia, graying, sclerodermatous skin changes, skin atrophy, osteoporosis, acro-osteolysis, joint contractures, small mandible, dental crowding, low muscle mass, joint stiffness, or mottled pigmentation of the skin, are highly suggestive of early aging syndromes. Of note, fat loss in the face of children may confer an aging appearance that should not be considered a progeroid trait. Once the above-reported conditions are excluded, the extent of fat loss and the distribution of residual adipose tissue must be defined. Localized lipoatrophy

characterized with an opposite distribution of fat. Localized forms of lipodystrophy are limited to small body areas.

After determining whether the lipodystrophy is generalized or partial, a further specification of the particular type of GLD or PLD can be undertaken. Numerous subtypes of GLD and PLD have been described, many associated with known genetic abnormalities (Table 1). may develop due to subcutaneous injection of certain drugs or as a result of regional panniculitis, in the absence of systemic manifestations. Extensive thinning of the subcutaneous adipose tissue should orientate towards a generalized form, whereas incomplete depletion of the adipose pad associated with fat accumulation in the spared regions indicates partial lipodystrophy. Both in generalized and partial lipodystrophies, occurrence of affected relatives or parental consanguinity indicates an inherited subtype of the disease, which should be confirmed by genetic testing. Fat loss in the lower body with fat accumulation in the face and neck is suggestive of FPLD, whereas lipoatrophy of the face that progresses to the shoulder girdle, upper extremities, and trunk is a sign of APL. Coexisting autoimmune diseases, panniculitis, or inflammatory manifestations (c: see text) at various sites advocate the diagnosis of acquired lipodystrophy that can be partial at early stages and then evolve as a generalized form. A history of total body irradiation, chemotherapy, and allogeneic bone marrow transplant in the context of leukemia treatment in childhood points to a specific subtype resembling FPLD. AGL acquired generalized lipodystrophy, $A P L$ acquired partial lipodystrophy, $C G L$ congenital generalized lipodystrophy, FPLD familial partial lipodystrophy

\section{Step 3.1: Evaluation of GLD}

CGL

GLD disorders of genetic origin include Berardinelli-Seip syndrome (usually referred to as CGL) and certain disorders of premature aging (progeroid syndromes). A key but nonpathognomonic characteristic to establish the presence of CGL is the age at onset of fat loss, which usually manifests at birth or during the first year of life. However, in some 
A

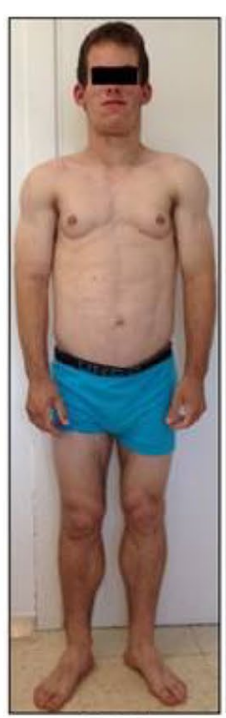

CGL

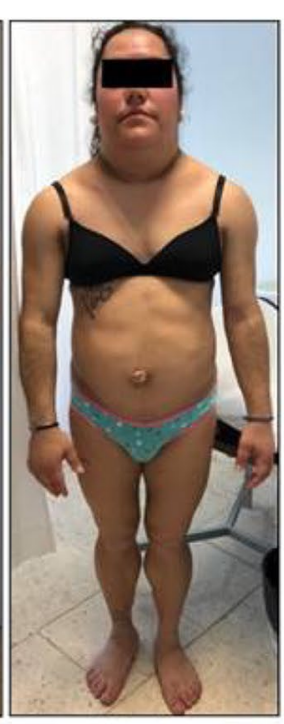

FPLD

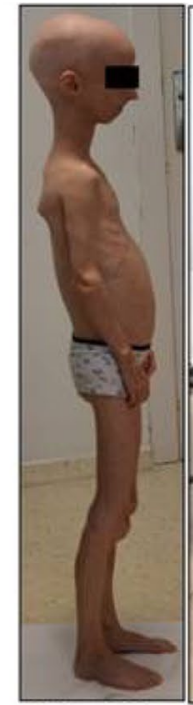

HGPS

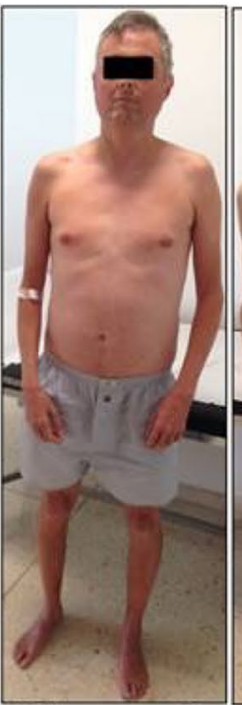

Werner S.

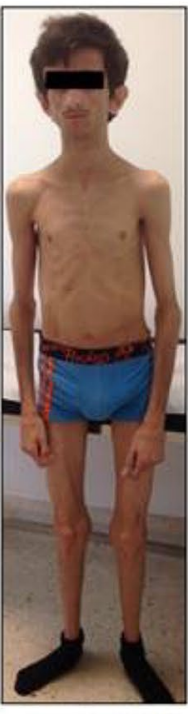

Atypical P. S.

B

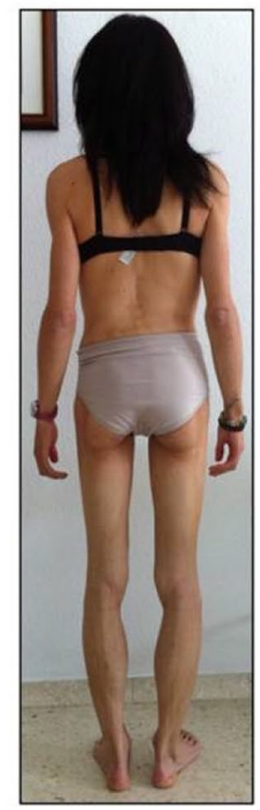

AGL

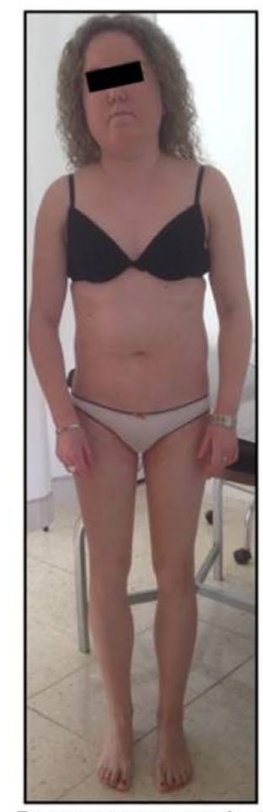

Bone marrow transplant associated lipodystrophy

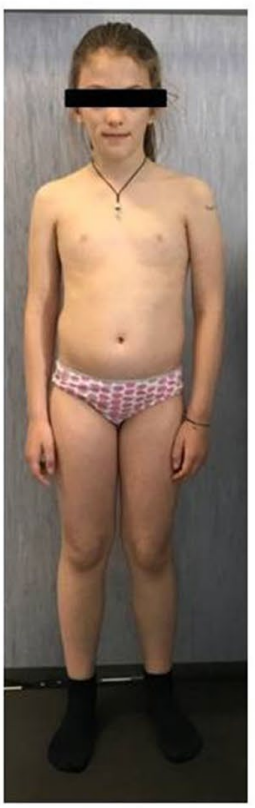

APL
Fig. 2 Physical appearance of patients with different lipodystrophy subtypes. a Congenital subtypes. Congenital generalized lipodystrophy (CGL): anterior view of a 15-year-old Caucasian man with type 2 CGL due to homozygous c.517dupA (p.Thr173AsnfsTer5) in the BSCL2 gene; familial partial lipodystrophy (FPLD): anterior view of a 27-year-old Caucasian woman with type 2 FPLD due to heterozygous c.1444C $>\mathrm{T}$ (p.Arg482Trp) in the LMNA gene; Hutchinson-Gilford progeria syndrome (HGPS): lateral view of a 16-year-old Caucasian woman with HGPS due to de novo heterozygous c.1824C $>\mathrm{T}$ (p.[=, Val607_Gln656del]) in the LMNA gene; Werner syndrome: anterior view of a 39-year-old Caucasian man with Werner syndrome due to compound heterozygous c.[2886dup]; [1982-5del]
(p.[Ile965*]; [Tyr660Ilefs7*]) in the RECQL2 gene; atypical progeria syndrome (PS): anterior view of a 17-year-old Caucasian man with atypical progeroid syndrome due to de novo heterozygous c.29C $>$ T (p.Thr10Ile) in the LMNA gene. b Acquired subtypes. Acquired generalized lipodystrophy (AGL): posterior view of a 35-year-old Caucasian woman with AGL; bone marrow transplant-associated lipodystrophy: anterior view of a 23-year-old Caucasian woman with partial lipodystrophy associated with bone marrow transplant and total body irradiation during childhood as a treatment for acute leukemia; acquired partial lipodystrophy (APL): anterior view of a 9-year-old Caucasian woman with APL 
CGL subtypes and progeria syndromes, lipodystrophy arises during childhood.

CGL is a rare autosomal recessive disorder associated with a near total absence of adipose tissue (Fig. 2a) [1, 10]. Patients have marked muscularity, apparent phlebomegaly, and acanthosis nigricans with acrochordons, which frequently extend beyond the axillae and neck and affect the groin, elbow flexion, and abdomen [1, 17]. Patients may exhibit acromegaloid features, beginning in adolescence. Abdominal distension due to hepatomegaly is usually seen from early childhood; hernia or umbilical protrusion is common $[1,9]$. In some cases, hypertrichosis is a prominent feature [9]. A voracious appetite is common in early childhood [4].

From the first months of disease, patients with CGL may present with hypertriglyceridemia that, if severe, can lead to acute pancreatitis [9]. Plasma insulin levels are elevated, and nonketotic diabetes, usually appearing in the second decade of life, is often very difficult to control, even with high doses of insulin [9]. Without treatment, the prognosis for patients with CGL is poor because of hepatic cirrhosis, cardiovascular complications of diabetes, pancreatitis, or end-stage renal disease [9].

The mean leptin level in patients with CGL is $1.0 \mathrm{ng} / \mathrm{mL}$ and is low regardless of sex and age [18].

In some cases, family history, and almost always phenotypic traits, of patients will help in diagnosis of CGL. Consanguinity should be assessed, because the presence of blood ties in the parents of the propositus would indicate CGL, and the presence of $\geq 1$ affected sibling would be almost confirmatory, when associated with phenotypic traits.

Certain clinical features may be associated with the gene responsible for each subtype of Berardinelli-Seip syndrome $[1,9]$ (Table 1), but genetic testing is required to confirm the type of CGL [1]. Types 1 (AGPAT2-associated) and 2 (BSCL2-associated) CGL are the most frequent, with type 2 having the most severe metabolic complications and an association with mental retardation $[9,10]$. In particular, some variants in BSCL2 are associated with lethal encephalopathy in early childhood [19]. Patients with CGL and BSCL2 variants have lower leptin levels and an earlier onset of diabetes than those without these variants [10]. Hypertrophic cardiomyopathy has been reported in types 1 and 2 CGL, as well as accelerated growth and, in women, clitoromegaly and precocious puberty $[9,20]$. Conversely, mechanical fat (e.g., palms and soles) is reduced in type 2 CGL, while it is conserved in other types [9,21].

Additional clinical features such as muscle mounding, muscle weakness, atlantoaxial instability, cardiac arrhythmias, osteopenia, distal metaphyseal deformation with joint stiffness, hypertrophic pyloric stenosis, and esophageal dysmotility can be highly suggestive of type 4 Berardinelli-Seip syndrome [22, 23], associated to variants in the PTRF gene.
In early childhood, Berardinelli-Seip syndrome may be confused with Rabson-Mendenhall syndrome and sometimes with Donohue syndrome (leprechaunism). Severe acanthosis nigricans and clitoromegaly can be confounding factors in the diagnosis. However, facial features in those with Rabson-Mendenhall syndrome are distinct and loss of fat, if any, is hardly evident. During adolescence or adulthood, some patients with Berardinelli-Seip syndrome have marked acromegaloid features. Absence of gigantism, generalized loss of subcutaneous fat, apparent hypermusculation, and severe insulin resistance make the differential diagnosis with acromegaly straightforward. If elements of doubt should persist, a normal suppression of serum growth hormone following administration of oral glucose is enough to exclude this disorder [24].

\section{Progeroid syndromes}

Contrasting with the genetically recessive nature of Berardinelli-Seip syndrome, progeroid syndromes associated with GLD may be dominant (usually de novo) or recessive [25-32] (Table 1). Some features, such as short stature, alopecia, graying, sclerodermatous skin changes, skin atrophy, osteoporosis, acro-osteolysis, joint contractures, small mandible, dental crowding, low muscle mass, joint stiffness, or mottled pigmentation of skin, among others, are highly suggestive of early aging syndromes [33]. For a description of subtypes, see specific references [25-32, 34] (Fig. 2a).

\section{AGL}

Compared with CGL, AGL (Lawrence syndrome) has a later onset (childhood or adolescence) and is more common in women than men (3:1 ratio) (Fig. 2b) [11]. The loss of adipose tissue occurring in childhood or adolescence, preceded or followed by autoimmune manifestations at various sites, may suggest a diagnosis of AGL [1]. Initially, subcutaneous fat loss may occur at limited locations, but it tends to generalize with progression of the disease over weeks, months, or years. Sometimes, facial fat loss is not initially present, although it usually occurs over time. In some cases, AGL is a phenocopy of Berardinelli-Seip syndrome.

Insulin-resistant diabetes, severe hypertriglyceridemia, hepatic steatosis, and insulin-resistance stigmata are frequent comorbidities of AGL. Hyperinsulinemia and low plasma leptin levels are typically present. Loss of fat in the palms and soles has been reported in approximately one-third and one-half of patients, respectively [11]. There is no family history of lipodystrophy in cases of AGL, but the presence of other autoimmune diseases in relatives may assist in the diagnosis. Activation of the classical complement pathway and low $\mathrm{C} 4$ complement levels have been associated with 
low leptin and adiponectin levels and with destruction of adipocytes and lipodystrophy in patients with AGL [35].

Three subtypes of AGL (panniculitis, autoimmune, and idiopathic) have been proposed [11]. Lipodystrophy onset has been associated with the appearance of panniculitis in $25 \%$ of cases and autoimmune disease in another $25 \%$ of cases, but no specific causes could be identified in most cases (idiopathic). Patients who developed AGL in association with autoimmune disease tended to be older than those with other AGL subtypes [11]. In particular, the autoimmune disease juvenile dermatomyositis has been associated with AGL [36]. Based on an analysis of a case series, disease associated with panniculitis may progress more slowly than either autoimmune or idiopathic AGL, with a lower prevalence of diabetes and hypertriglyceridemia [11].

\section{Step 3.2: Evaluation of PLD}

The distribution of fat loss, age of onset, certain phenotypic traits, and family history are determining factors in diagnosing the subtypes of PLD, which include congenital and acquired disorders (Table 1).

\section{PLD of genetic origin}

PLD disorders of genetic origin are described further in the following sections and include FPLD, certain progeroid syndromes, and autoinflammatory syndromes. Many forms of PLD are associated with known genetic abnormalities, and genetic tests are needed to confirm the presence of currently identified mutations in some PLD subtypes [1].

FPLD FPLD encompasses a number of conditions sharing a Cushingoid appearance and a variable association with excess body weight (Fig. 2a). The loss of subcutaneous fat in the limbs and gluteal region, observed around childhood or puberty and associated with accumulation of excess fat in the face, neck, and intra-abdominal region, is suggestive of FPLD [9].

Eight subtypes of FPLD have been reported [17] (Table 1). Type 1 FPLD (Köbberling syndrome) is an earlyonset, inherited variety of PLD, although no specific genes are known to be involved, and a dominant or polygenic pathogenesis has been suggested [12, 37, 38]. The diagnosis of type 1 FPLD is challenging because it can be easily confused with android obesity in women associated with metabolic syndrome. Patients with type 1 FPLD are usually obese and have a significant accumulation of abdominal fat, with lipoatrophy most evident in the hips and lower extremities [12]. The disease may represent part of a spectrum encompassing essential central obesity, and specific cutoffs for thickness and distribution of SAT that can be useful for clinical purposes have been proposed [12].

The classic phenotype of FPLD (type 2, Dunnigan disease) is currently attributed to variants in exon 8 of the LMNA gene. Fat loss begins around puberty in women and often goes unnoticed in men because of the particular distribution of body fat. Affected men are often diagnosed when an affected female relative is identified. Fat loss is present in the limbs, trunk, hips, and buttocks. Strikingly, these patients have accumulation of fat in the face, neck, axillae, interscapular region, abdominal visceral area, and labia majora [39]. The musculature is well defined and may even include muscular hypertrophy in the calves, as well as apparent phlebomegaly.

Patients with type 2 FPLD, especially women, frequently present with early insulin resistance that may lead to diabetes, hypertriglyceridemia (sometimes severe and causing acute pancreatitis), low high-density lipoprotein cholesterol, hepatic steatosis, and an increased risk of cardiovascular disease; sometimes these patients also present with acanthosis nigricans (although not as severe as in GLD). PCOS is not uncommon, as well as obstetric problems (i.e., gestational diabetes, miscarriage, and stillbirth), muscle aches, and lipomas $[39,40]$.

Family history (dominant vs. recessive) and certain phenotypic traits and associated disorders may guide molecular diagnosis. For example, in type 2 FPLD there may be valvular heart disease, myocardial hypertrophy, and/or cardiac conduction system disorders. Other laminopathies (Emery-Dreifuss muscular dystrophy, limb-girdle muscular dystrophy, or familial dilated cardiomyopathy) may also be associated with type 2 FPLD or even be present in other family members [41]. Thus, a careful cardiac evaluation is encouraged. Mutations in exons other than exon 8 in LMNA can lead to atypical forms of type 2 FPLD, in which lipodystrophy is less evident, or can even be confused with Köbberling syndrome.

In type 3 FPLD, lipoatrophy appears in adulthood, with no fat accumulation in the face or neck. Cardiometabolic complications are usually severe [42]. In type 4 FPLD, lipoatrophy appears in childhood or in adulthood, with possible accumulation of facial fat. These patients also exhibit severe dyslipidemia and insulin-resistant diabetes [43].

Types 5 and 6 FPLD are recessive conditions, and only a few cases have been reported [44-46]. Type 5 FPLD appears in early childhood, while type 6 appears in adulthood. In type 5 FPLD, there is muscular hypertrophy but no accumulation of adipose tissue. Accumulation of fat in the neck, axillae, back, and supraclavicular area; muscular dystrophy (weakness); elevation of creatine kinase; and hypertriglyceridemia have been reported in type 6 FPLD. Because of this particular fat distribution, FPLD must be differentiated from Cushing syndrome. Chronic hypercortisolism causes 
a characteristic centripetal fat distribution [47], but no particular changes in limb fat have been reported, and muscle wasting is evident [48].

Progeroid syndromes Progeroid syndromes associated with PLD are shown in Table 1 (Fig. 2a) [49-55]. All of these syndromes have particular clinical features of early aging, the detailed description of which is beyond the scope of this review.

Autoinflammatory syndromes Autoinflammatory syndromes causing lipodystrophy include Nakajo-Nishimura syndrome; joint contractures, muscle atrophy, microcytic anemia, and panniculitis-induced lipodystrophy (JMP) syndrome; and chronic atypical neutrophilic dermatosis with lipodystrophy and elevated temperature (CANDLE) syndrome. These disorders begin in childhood, and the lipodystrophy can be generalized or partial, affecting the face and limbs. All are recessive disorders related to mutations in genes encoding for proteins that are essential for the maturation and assembly of the proteasome subunits [56-58]. Normally, type 1 interferon secreted by cells after viral infection or other triggers activates the JAK/STAT pathway that produces reactive oxygen and nitrogen species with defensive function. These oxidant molecules may be detrimental to functional integrity of cell proteins and are usually removed by the proteasome-immunoproteasome system. In autoinflammatory syndromes, cells with mutated proteasome-immunoproteasome will not be able to remove all waste proteins. As a result, an abnormal cellular stress occurs, leading to additional type 1 interferon production and perpetuation of tissue damage [59].

Nakajo-Nishimura syndrome is an inflammatory disease involving lipomuscular atrophy and joint contractures [57]. As indicated by its name, JMP syndrome is characterized by joint contractures, muscular atrophy, microcytic anemia, and panniculitis-induced lipodystrophy [60]. Other characteristics include intermittent fever, hypergammaglobulinemia, increased sedimentation rate, hepatosplenomegaly, and calcification of the basal ganglia. In CANDLE syndrome, patients present with childhood-onset recurrent fevers and violaceous annular plaques on the eyelids and lips, evolving through childhood to a loss of subcutaneous fat in the face and upper limbs. Patients also have hepatosplenomegaly, arthralgias, microcytic anemia, increased sedimentation rate, and calcifications in the basal ganglia [61].

\section{APL}

APL includes HIV-associated lipodystrophy, BarraquerSimons syndrome, and bone marrow transplant-associated lipodystrophy. While lipodystrophy in patients with HIV receiving long-term antiretroviral therapy is the most common form of lipodystrophy [62], it is out of the scope of this review.

Barraquer-Simons syndrome Barraquer-Simons syndrome is a very rare disorder of unknown etiology (possibly autoimmune) characterized by a cephalocaudal loss of SAT. It is more common in women than men (4:1 ratio) (Fig. 2b), and fat loss usually begins in late childhood or adolescence. Fat loss initially affects the head, giving children an aged appearance, and progresses to the shoulder girdle, upper extremities, and trunk [1] in a process that can last weeks, months, or years. When affected women gain weight, they accumulate fat in the lower extremities, presenting a unique phenotype of APL. The arms have well-defined musculature and apparent phlebomegaly. Acanthosis nigricans is generally absent [6]. Although the etiology of APL is unknown, the presence of other autoimmune diseases may help confirm the diagnosis, in particular membranoproliferative glomerulonephritis, which can lead to kidney failure [1].

Although reports of metabolic complications have generally been uncommon in Barraquer-Simons syndrome [6], a recent study suggests that these complications have been underestimated [63]. Patients tend to have low serum C3 complement and leptin levels and detectable $\mathrm{C} 3$ nephritic factor [6].

\section{Bone marrow transplant-associated lipodystro-}

phy Recently, lipodystrophy following total body irradiation, chemotherapy, and allogeneic bone marrow transplant has been reported as a phenocopy of FPLD [64-66]. This form of APL affects patients who underwent bone marrow transplant in the context of leukemia treatment in childhood (Fig. 2b).

\section{Localized lipodystrophy disorders}

Localized lipodystrophy disorders involve small amounts of fat loss due to drugs, panniculitis, or unknown etiology [17]. The amount of fat loss is minimal; therefore, these disorders are not associated with metabolic abnormalities.

\section{Complications of lipodystrophy}

Deficient adipose mass in lipodystrophy results in a collection of typical metabolic complications that include insulin resistance and diabetes, hypertriglyceridemia, PCOS, and nonalcoholic fatty liver disease [1]. In patients with lipodystrophy, these complications are sequelae of the defects that led to altered adiposity [1]. Causes of premature mortality include cardiovascular disease, liver disease, kidney failure, pancreatitis, and sepsis $[1,11,67,68]$. 


\section{Treatment approach for lipodystrophy}

Lipodystrophy is a progressive and life-threatening disease. Currently, there is no cure for lipodystrophy. Metabolic comorbidities must be treated to manage the short- and longterm complications of the disease.

\section{Treatment of comorbidities}

Diet and exercise are important factors in managing lipodystrophy comorbidities. Practice guidelines recommend that patients adhere to a balanced diet, including 50 to $60 \%$ carbohydrates, $20-30 \%$ fat, and 20\% protein. Because hypoleptinemia (absolute or relative) stimulates appetite and food consumption, energy restriction is usually recommended to reduce ectopic fat storage and improve metabolic abnormalities, although it may be difficult to achieve, especially in childhood and adolescence. Of note, growth assessment may be challenging because of the abnormal body composition and the underlying primary disease that may affect linear growth independent of lipodystrophy. Very low-fat diets should be used in patients with acute pancreatitis. Physical exercise should be advised, if not contraindicated by concurrent diseases, but limitations may intervene because of musculoskeletal pain, fatigue, or psychological distress [1]. Plastic surgery (breast implants, dermal fillers, lipectomy, or liposuction) and psychological support can improve the well-being of some patients.

In addition to lifestyle changes, patients with lipodystrophy should receive medical treatment for specific metabolic comorbidities. Clinicians should follow national or international guidelines in the diagnosis and management of diabetes, dyslipidemia, hypertension, and renal and hepatic disease. As discussed in the next section, leptin replacement therapy may reduce the need for treatment of metabolic comorbidities.

\section{Leptin replacement therapy}

Metreleptin (Myalept ${ }^{\circledR}$, Aegerion Pharmaceuticals, Cambridge, MA, USA) is the only drug indicated specifically for the treatment of lipodystrophy, although many therapies are used to treat comorbid conditions. Metreleptin is a leptin analogue indicated in the United States as an adjunct to diet as replacement therapy to treat the complications of leptin deficiency in patients with CGL or AGL [69]. Metreleptin has been submitted to the European Medicines Agency for approval in the treatment of patients with CGL, AGL, and certain types of PLD.

\section{Metreleptin for GLD}

Patients receiving metreleptin typically report an immediate decrease in appetite and reduction in food intake [70]. Metreleptin treatment has been associated with an improved metabolic profile in patients with GLD [71]. An open-label cohort study conducted at the National Institutes of Health (NIH) reported reductions in hemoglobin A1c (HbA1c), fasting plasma glucose, and triglycerides within 4 months of initiating treatment, which were maintained for $\geq 3$ years in patients with CGL or AGL and at least 1 of 3 metabolic abnormalities (diabetes, insulin resistance, and/or hypertriglyceridemia) [71, 72]. Patients receiving metreleptin were often able to eliminate or greatly reduce the dosage of their antidiabetes medications [73]. The long-term improvements in metabolic parameters continued to accrue even after reduction or discontinuation of antidiabetic therapy $[73,74]$.

Leptin replacement therapy is also associated with decreased liver volume and serum aminotransferase levels $[71,73,74]$. Paired biopsy studies have shown that nonalcoholic steatohepatitis associated with GLD was ameliorated with metreleptin treatment $[75,76]$. During 52 weeks of metreleptin treatment, improved brain connectivity associated with hedonic and homeostatic control of eating behavior, decreased hunger, and increased satiety were observed [77].

\section{Metreleptin for PLD}

Use of metreleptin in PLD, whether congenital or acquired, is off-label in the United States as of the writing of this review. However, data suggest that the drug may be beneficial in a subset of patients with PLD. Metreleptin treatment was associated with normalization of serum leptin levels within 3 months and decreased triglycerides but not improvement in glycemic control in patients with moderate or severe hypoleptinemia and FPLD (Dunnigan variety) [78]. In the NIH study, metabolic parameters improved over 1 year of treatment with metreleptin in patients with PLD; however, the magnitude of reduction in metabolic parameters was less than that observed in patients with GLD [2].

Some findings suggest that patients with severe PLD may benefit most from leptin replacement therapy. In an analysis from the NIH cohort, metreleptin appeared more effective in patients with higher (vs. lower) baseline metabolic thresholds (baseline $\mathrm{HbA} 1 \mathrm{c}>7.0$ or $>8.0 \%$, triglycerides $>300$ or $>500 \mathrm{mg} / \mathrm{dL}$, and leptin $<4 \mathrm{ng} / \mathrm{mL}$ ) [2]. In a separate study, a small subset of patients with severe abnormalities at baseline (HbA1c $\geq 8.0 \%$ or triglycerides $\geq 500 \mathrm{mg} / \mathrm{dL}$ ) who were treated with metreleptin for 1 year appeared to derive substantial benefit from treatment compared with the overall treated population [79]. 


\section{Efficacy of metreleptin in children with lipodystrophy}

There is some evidence that metreleptin is effective in pediatric patients with GLD or PLD. Improvements in glycemic parameters, triglycerides, liver histology, and markers of liver health were achieved over 1 year of treatment in 53 patients with GLD or PLD and were maintained throughout a mean follow-up of 5 years in the NIH cohort [80]. Metreleptin therapy did not accelerate or trigger puberty, and it was associated with normalization of growth trajectory in this cohort. However, only 8 patients with PLD were included, 7 of which were $>12$ years old, which limits generalizing this finding among younger children with PLD.

\section{Metreleptin tolerability}

The most frequent adverse events associated with metreleptin among patients with GLD $(n=48)$ receiving treatment for a median of 2.7 years were headache (13\%), hypoglycemia (13\%), and decreased weight (13\%) [69]. In the same study, antimetreleptin antibodies were detected in 36 of 43 patients examined, and 2 individuals had neutralizing antibodies, which were associated with infection and loss of metabolic control [69]. Risks of neutralizing antibodies are unclear and should be weighed alongside the benefits of therapy [70].

Lymphoma has been reported in patients with AGL, both in the absence and presence of metreleptin treatment [81]. The increased risk of malignancy in these individuals may be attributable to autoimmune disease; however, a role of metreleptin in tumor growth cannot be ruled out [81].

\section{Conclusions}

Lipodystrophy disorders are a diverse collection of rare congenital or acquired disorders of adipose tissue that range from mild to severe, result in fat loss and metabolic disease, and many are characterized by leptin deficiency. Because lipodystrophy is an ultra-rare disease, it is possible that the practicing clinician will never encounter a patient with GLD or PLD; however, the phenotype and presentation are sufficiently distinct that such patients can be recognized and diagnosed in most instances. Standard of care for lipodystrophy includes treatment with leptin replacement if indicated, aggressive treatment of comorbidities such as diabetes and dyslipidemia, and genetic screening of relatives, if warranted.

Author contributions DA-V and FS each guided the planning and development of the manuscript content, drafted sections of the paper, critically reviewed and revised the content, and approved the final version.

Funding Aegerion provided funding for medical writing and/or editing support in the development of this manuscript; Blair Jarvis, MSc, ELS, and Lisa Baker, PhD, from inScience Communications, (Springer Healthcare, Philadelphia, PA), based on input from authors, wrote the first draft and revised subsequent drafts of the manuscript. Aegerion reviewed and provided feedback to the authors. The authors had full editorial control of the manuscript, fully developed the diagnostic algorithm, and provided their final approval of all content. The authors confirm independence from the sponsor; the content of the article has not been influenced by the sponsor. David Araújo-Vilar was supported by the intramural research program of the Xunta de Galicia (Programa de Consolidación e Estructuración de Unidades de Investigación Competitivas; Grant ED341b 2017/19).

\section{Compliance with ethical standards}

All named authors meet the International Committee of Medical Journal Editors (ICMJE) criteria for authorship for this manuscript and take responsibility for the integrity of the work as a whole.

Conflict of interest David Araújo-Vilar and Ferruccio Santini have received honoraria as scientific advisors from Aegerion Pharmaceuticals.

Ethical approval This article does not contain any studies with human participants or animals performed by any of the authors.

Informed consent A written consent was obtained from the patients for the publication of their photographs.

Open Access This article is distributed under the terms of the Creative Commons Attribution 4.0 International License (http://creativeco mmons.org/licenses/by/4.0/), which permits unrestricted use, distribution, and reproduction in any medium, provided you give appropriate credit to the original author(s) and the source, provide a link to the Creative Commons license, and indicate if changes were made.

\section{References}

1. Brown RJ, Araujo-Vilar D, Cheung PT, Dunger D, Garg A, Jack M, Mungai L, Oral EA, Patni N, Rother KI, von Schnurbein J, Sorkina E, Stanley T, Vigouroux C, Wabitsch M, Williams R, Yorifuji T (2016) The diagnosis and management of lipodystrophy syndromes: a multi-society practice guideline. J Clin Endocrinol Metab 101:4500-4511

2. Diker-Cohen T, Cochran E, Gorden P, Brown RJ (2015) Partial and generalized lipodystrophy: comparison of baseline characteristics and response to metreleptin. J Clin Endocrinol Metab 100:1802-1810

3. Haque WA, Shimomura I, Matsuzawa Y, Garg A (2002) Serum adiponectin and leptin levels in patients with lipodystrophies. $\mathbf{J}$ Clin Endocrinol Metab 87:2395

4. Garg A (2004) Acquired and inherited lipodystrophies. N Engl J Med 350:1220-1234

5. Chiquette E, Oral EA, Garg A, Araújo-Vilar D, Dhankhar P (2017) Estimating the prevalence of generalized and partial lipodystrophy: findings and challenges. Diabetes Metab Syndr Obes 10:375-383 
6. Misra A, Peethambaram A, Garg A (2004) Clinical features and metabolic and autoimmune derangements in acquired partial lipodystrophy: report of 35 cases and review of the literature. Medicine (Baltimore) 83:18-34

7. Vantyghem MC, Balavoine AS, Douillard C, Defrance F, Dieudonne L, Mouton F, Lemaire C, Bertrand-Escouflaire N, Bourdelle-Hego MF, Devemy F, Evrard A, Gheerbrand D, Girardot C, Gumuche S, Hober C, Topolinski H, Lamblin B, Mycinski B, Ryndak A, Karrouz W, Duvivier E, Merlen E, Cortet C, Weill J, Lacroix D, Wemeau JL (2012) How to diagnose a lipodystrophy syndrome. Ann Endocrinol (Paris) 73:170-189

8. Patni N, Alves C, von Schnurbein J, Wabitsch M, Tannin G, Rakheja D, Garg A (2015) A novel syndrome of generalized lipodystrophy associated with pilocytic astrocytoma. J Clin Endocrinol Metab 100:3603-3606

9. Garg A (2011) Clinical review\#: lipodystrophies: genetic and acquired body fat disorders. J Clin Endocrinol Metab 96:3313-3325

10. Agarwal AK, Simha V, Oral EA, Moran SA, Gorden P, O'Rahilly S, Zaidi Z, Gurakan F, Arslanian SA, Klar A, Ricker A, White NH, Bindl L, Herbst K, Kennel K, Patel SB, Al-Gazali L, Garg A (2003) Phenotypic and genetic heterogeneity in congenital generalized lipodystrophy. J Clin Endocrinol Metab 88:4840-4847

11. Misra A, Garg A (2003) Clinical features and metabolic derangements in acquired generalized lipodystrophy: case reports and review of the literature. Medicine (Baltimore) 82:129-146

12. Guillin-Amarelle C, Sanchez-Iglesias S, Castro-Pais A, Rodriguez-Canete L, Ordonez-Mayan L, Pazos M, Gonzalez-Mendez B, Rodriguez-Garcia S, Casanueva FF, Fernandez-Marmiesse A, Araujo-Vilar D (2016) Type 1 familial partial lipodystrophy: understanding the Kobberling syndrome. Endocrine 54:411-421

13. Garg A, Fleckenstein JL, Peshock RM, Grundy SM (1992) Peculiar distribution of adipose tissue in patients with congenital generalized lipodystrophy. J Clin Endocrinol Metab 75:358-361

14. Nijim Y, Awni Y, Adawi A, Bowirrat A (2016) Classic case report of Donohue syndrome (leprechaunism; OMIM *246200): the impact of consanguineous mating. Medicine (Baltimore) 95:e2710

15. UpToDate (2017) Lipodystrophic syndromes. https://www.uptod ate.com/contents/lipodystrophic-syndromes

16. West RJ, Lloyd JK, Turner WM (1975) Familial insulin-resistant diabetes, multiple somatic anomalies, and pineal hyperplasia. Arch Dis Child 50:703-708

17. Hussain I, Garg A (2016) Lipodystrophy syndromes. Endocrinol Metab Clin N Am 45:783-797

18. Lima JG, Nobrega LH, de Lima NN, do Nascimento Santos MG, Baracho MF, Jeronimo SM (2016) Clinical and laboratory data of a large series of patients with congenital generalized lipodystrophy. Diabetol Metab Syndr 8:23

19. Guillen-Navarro E, Sanchez-Iglesias S, Domingo-Jimenez R, Victoria B, Ruiz-Riquelme A, Rabano A, Loidi L, Beiras A, Gonzalez-Mendez B, Ramos A, Lopez-Gonzalez V, BallestaMartinez MJ, Garrido-Pumar M, Aguiar P, Ruibal A, Requena JR, Araujo-Vilar D (2013) A new seipin-associated neurodegenerative syndrome. J Med Genet 50:401-409

20. Van Maldergem L, Magre J, Khallouf TE, Gedde-Dahl T Jr, Delepine M, Trygstad O, Seemanova E, Stephenson T, Albott CS, Bonnici F, Panz VR, Medina JL, Bogalho P, Huet F, Savasta S, Verloes A, Robert JJ, Loret H, De Kerdanet M, Tubiana-Rufi N, Megarbane A, Maassen J, Polak M, Lacombe D, Kahn CR, Silveira EL, D'Abronzo FH, Grigorescu F, Lathrop M, Capeau J, O'Rahilly S (2002) Genotype-phenotype relationships in Berardinelli-Seip congenital lipodystrophy. J Med Genet 39:722-733

21. Simha V, Garg A (2003) Phenotypic heterogeneity in body fat distribution in patients with congenital generalized lipodystrophy caused by mutations in the AGPAT2 or seipin genes. J Clin Endocrinol Metab 88:5433-5437

22. Hayashi YK, Matsuda C, Ogawa M, Goto K, Tominaga K, Mitsuhashi S, Park YE, Nonaka I, Hino-Fukuyo N, Haginoya K, Sugano H, Nishino I (2009) Human PTRF mutations cause secondary deficiency of caveolins resulting in muscular dystrophy with generalized lipodystrophy. J Clin Invest 119:2623-2633

23. Rajab A, Straub V, McCann LJ, Seelow D, Varon R, Barresi R, Schulze A, Lucke B, Lutzkendorf S, Karbasiyan M, Bachmann S, Spuler S, Schuelke M (2010) Fatal cardiac arrhythmia and longQT syndrome in a new form of congenital generalized lipodystrophy with muscle rippling (CGL4) due to PTRF-CAVIN mutations. PLoS Genet 6:e1000874

24. Trainer PJ, Besser GM (1995) The Bart's Endocrine Protocols. Churchill Livingstone, Edinburgh

25. Cabanillas R, Cadinanos J, Villameytide JA, Perez M, Longo J, Richard JM, Alvarez R, Duran NS, Illan R, Gonzalez DJ, Lopez-Otin C (2011) Nestor-Guillermo progeria syndrome: a novel premature aging condition with early onset and chronic development caused by BANF1 mutations. Am J Med Genet A 155a:2617-2625

26. Csoka AB, Cao H, Sammak PJ, Constantinescu D, Schatten GP, Hegele RA (2004) Novel lamin A/C gene (LMNA) mutations in atypical progeroid syndromes. J Med Genet 41:304-308

27. Cunningham VJ, D'Apice MR, Licata N, Novelli G, Cundy T (2010) Skeletal phenotype of mandibuloacral dysplasia associated with mutations in ZMPSTE24. Bone 47:591-597

28. Dyment DA, Smith AC, Alcantara D, Schwartzentruber JA, BaselVanagaite L, Curry CJ, Temple IK, Reardon W, Mansour S, Haq MR, Gilbert R, Lehmann OJ, Vanstone MR, Beaulieu CL, Majewski J, Bulman DE, O’Driscoll M, Boycott KM, Innes AM (2013) Mutations in PIK3R1 cause SHORT syndrome. Am J Hum Genet 93:158-166

29. Laugel V (2013) Cockayne syndrome: the expanding clinical and mutational spectrum. Mech Ageing Dev 134:161-170

30. Lessel D, Vaz B, Halder S, Lockhart PJ, Marinovic-Terzic I, Lopez-Mosqueda J, Philipp M, Sim JC, Smith KR, Oehler J, Cabrera E, Freire R, Pope K, Nahid A, Norris F, Leventer RJ, Delatycki MB, Barbi G, von Ameln S, Hogel J, Degoricija M, Fertig R, Burkhalter MD, Hofmann K, Thiele H, Altmuller J, Nurnberg G, Nurnberg P, Bahlo M, Martin GM, Aalfs CM, Oshima J, Terzic J, Amor DJ, Dikic I, Ramadan K, Kubisch C (2014) Mutations in SPRTN cause early onset hepatocellular carcinoma, genomic instability and progeroid features. Nat Genet 46:1239-1244

31. Masotti A, Uva P, Davis-Keppen L, Basel-Vanagaite L, Cohen L, Pisaneschi E, Celluzzi A, Bencivenga P, Fang M, Tian M, Xu X, Cappa M, Dallapiccola B (2015) Keppen-Lubinsky syndrome is caused by mutations in the inwardly rectifying $\mathrm{K}+$ channel encoded by KCNJ6. Am J Hum Genet 96:295-300

32. Nicolas E, Golemis EA, Arora S (2016) POLD1: central mediator of DNA replication and repair, and implication in cancer and other pathologies. Gene 590:128-141

33. Oshima J, Martin GM, Hisama FM (1993) Werner syndrome. In: Pagon RA, Adam MP, Ardinger HH, Wallace SE, Amemiya A, Bean LJH, Bird TD, Ledbetter N, Mefford HC, Smith RJH, Stephens K (eds) GeneReviews ${ }^{\circledR}$. University of Washington, Seattle

34. Hennekam RC (2006) Hutchinson-Gilford progeria syndrome: review of the phenotype. Am J Med Genet A 140:2603-2624

35. Savage DB, Semple RK, Clatworthy MR, Lyons PA, Morgan BP, Cochran EK, Gorden P, Raymond-Barker P, Murgatroyd PR, Adams C, Scobie I, Mufti GJ, Alexander GJ, Thiru S, Murano I, Cinti S, Chaudhry AN, Smith KG, O'Rahilly S (2009) Complement abnormalities in acquired lipodystrophy revisited. J Clin Endocrinol Metab 94:10-16 
36. Huemer C, Kitson H, Malleson PN, Sanderson S, Huemer M, Cabral DA, Chanoine JP, Petty RE (2001) Lipodystrophy in patients with juvenile dermatomyositis-evaluation of clinical and metabolic abnormalities. J Rheumatol 28:610-615

37. Kobberling J, Dunnigan MG (1986) Familial partial lipodystrophy: two types of an $\mathrm{X}$ linked dominant syndrome, lethal in the hemizygous state. J Med Genet 23:120-127

38. Lotta LA, Gulati P, Day FR, Payne F, Ongen H, van de Bunt M, Gaulton KJ, Eicher JD, Sharp SJ, Luan J, De Lucia Rolfe E, Stewart ID, Wheeler E, Willems SM, Adams C, Yaghootkar H, Consortium EP-I, Cambridge FC, Forouhi NG, Khaw KT, Johnson AD, Semple RK, Frayling T, Perry JR, Dermitzakis E, McCarthy MI, Barroso I, Wareham NJ, Savage DB, Langenberg C, O'Rahilly S, Scott RA (2017) Integrative genomic analysis implicates limited peripheral adipose storage capacity in the pathogenesis of human insulin resistance. Nat Genet 49:17-26

39. Bidault G, Vatier C, Capeau J, Vigouroux C, Bereziat V (2011) LMNA-linked lipodystrophies: from altered fat distribution to cellular alterations. Biochem Soc Trans 39:1752-1757

40. Araujo-Vilar D, Victoria B, Gonzalez-Mendez B, Barreiro F, Fernandez-Rodriguez B, Cereijo R, Gallego-Escuredo JM, Villarroya F, Paneda-Menendez A (2012) Histological and molecular features of lipomatous and nonlipomatous adipose tissue in familial partial lipodystrophy caused by LMNA mutations. Clin Endocrinol (Oxf) 76:816-824

41. Subramanyam L, Simha V, Garg A (2010) Overlapping syndrome with familial partial lipodystrophy, Dunnigan variety and cardiomyopathy due to amino-terminal heterozygous missense lamin A/C mutations. Clin Genet 78:66-73

42. Semple RK, Chatterjee VK, O'Rahilly S (2006) PPAR gamma and human metabolic disease. J Clin Invest 116:581-589

43. Gandotra S, Le Dour C, Bottomley W, Cervera P, Giral P, Reznik Y, Charpentier G, Auclair M, Delepine M, Barroso I, Semple RK, Lathrop M, Lascols O, Capeau J, O'Rahilly S, Magre J, Savage DB, Vigouroux C (2011) Perilipin deficiency and autosomal dominant partial lipodystrophy. N Engl J Med 364:740-748

44. Farhan SM, Robinson JF, McIntyre AD, Marrosu MG, Ticca AF, Loddo S, Carboni N, Brancati F, Hegele RA (2014) A novel LIPE nonsense mutation found using exome sequencing in siblings with late-onset familial partial lipodystrophy. Can J Cardiol 30:1649-1654

45. Rubio-Cabezas O, Puri V, Murano I, Saudek V, Semple RK, Dash S, Hyden CS, Bottomley W, Vigouroux C, Magre J, RaymondBarker P, Murgatroyd PR, Chawla A, Skepper JN, Chatterjee VK, Suliman S, Patch AM, Agarwal AK, Garg A, Barroso I, Cinti S, Czech MP, Argente J, O'Rahilly S, Savage DB (2009) Partial lipodystrophy and insulin resistant diabetes in a patient with a homozygous nonsense mutation in CIDEC. EMBO Mol Med $1: 280-287$

46. Zolotov S, Xing C, Mahamid R, Shalata A, Sheikh-Ahmad M, Garg A (2017) Homozygous LIPE mutation in siblings with multiple symmetric lipomatosis, partial lipodystrophy, and myopathy. Am J Med Genet A 173:190-194

47. Garrapa GG, Pantanetti P, Arnaldi G, Mantero F, Faloia E (2001) Body composition and metabolic features in women with adrenal incidentaloma or Cushing's syndrome. J Clin Endocrinol Metab 86:5301-5306

48. Rockall AG, Sohaib SA, Evans D, Kaltsas G, Isidori AM, Monson JP, Besser GM, Grossman AB, Reznek RH (2003) Computed tomography assessment of fat distribution in male and female patients with Cushing's syndrome. Eur J Endocrinol 149:561-567

49. Donadille B, D'Anella P, Auclair M, Uhrhammer N, Sorel M, Grigorescu R, Ouzounian S, Cambonie G, Boulot P, Laforet P, Carbonne B, Christin-Maitre S, Bignon YJ, Vigouroux C (2013)
Partial lipodystrophy with severe insulin resistance and adult progeria Werner syndrome. Orphanet J Rare Dis 8:106

50. Garg A, Kircher M, Del Campo M, Amato RS, Agarwal AK (2015) Whole exome sequencing identifies de novo heterozygous CAV1 mutations associated with a novel neonatal onset lipodystrophy syndrome. Am J Med Genet A 167a:1796-1806

51. Novelli G, Muchir A, Sangiuolo F, Helbling-Leclerc A, D'Apice MR, Massart C, Capon F, Sbraccia P, Federici M, Lauro R, Tudisco C, Pallotta R, Scarano G, Dallapiccola B, Merlini L, Bonne G (2002) Mandibuloacral dysplasia is caused by a mutation in LMNA-encoding lamin A/C. Am J Hum Genet 71:426-431

52. Paolacci S, Bertola D, Franco J, Mohammed S, Tartaglia M, Wollnik B, Hennekam RC (2017) Wiedemann-Rautenstrauch syndrome: a phenotype analysis. Am J Med Genet A. https://doi. org/10.1002/ajmg.a.38246 (epub ahead of print)

53. Payne F, Lim K, Girousse A, Brown RJ, Kory N, Robbins A, Xue Y, Sleigh A, Cochran E, Adams C, Dev Borman A, RusselJones D, Gorden P, Semple RK, Saudek V, O'Rahilly S, Walther TC, Barroso I, Savage DB (2014) Mutations disrupting the Kennedy phosphatidylcholine pathway in humans with congenital lipodystrophy and fatty liver disease. Proc Natl Acad Sci USA 111:8901-8906

54. Pelosini C, Martinelli S, Ceccarini G, Magno S, Barone I, Basolo A, Fierabracci P, Vitti P, Maffei M, Santini F (2014) Identification of a novel mutation in the polymerase delta 1 (POLD1) gene in a lipodystrophic patient affected by mandibular hypoplasia, deafness, progeroid features (MDPL) syndrome. Metabolism 63:1385-1389

55. Weedon MN, Ellard S, Prindle MJ, Caswell R, Lango Allen H, Oram R, Godbole K, Yajnik CS, Sbraccia P, Novelli G, Turnpenny P, McCann E, Goh KJ, Wang Y, Fulford J, McCulloch LJ, Savage DB, O'Rahilly S, Kos K, Loeb LA, Semple RK, Hattersley AT (2013) An in-frame deletion at the polymerase active site of POLD1 causes a multisystem disorder with lipodystrophy. Nat Genet 45:947-950

56. Agarwal AK, Xing C, DeMartino GN, Mizrachi D, Hernandez MD, Sousa AB, Martinez de Villarreal L, dos Santos HG, Garg A (2010) PSMB8 encoding the beta5i proteasome subunit is mutated in joint contractures, muscle atrophy, microcytic anemia, and panniculitis-induced lipodystrophy syndrome. Am J Hum Genet $87: 866-872$

57. Arima K, Kinoshita A, Mishima H, Kanazawa N, Kaneko T, Mizushima T, Ichinose K, Nakamura H, Tsujino A, Kawakami A, Matsunaka M, Kasagi S, Kawano S, Kumagai S, Ohmura K, Mimori T, Hirano M, Ueno S, Tanaka K, Tanaka M, Toyoshima I, Sugino H, Yamakawa A, Tanaka K, Niikawa N, Furukawa F, Murata S, Eguchi K, Ida H, Yoshiura K (2011) Proteasome assembly defect due to a proteasome subunit beta type 8 (PSMB8) mutation causes the autoinflammatory disorder, Nakajo-Nishimura syndrome. Proc Natl Acad Sci USA 108:14914-14919

58. Kluk J, Rustin M, Brogan PA, Omoyinmi E, Rowczenio DM, Willcocks LC, Melly L, Lachmann HJ (2014) Chronic atypical neutrophilic dermatosis with lipodystrophy and elevated temperature syndrome: a report of a novel mutation and review of the literature. Br J Dermatol 170:215-217

59. Torrelo A (2017) CANDLE syndrome as a paradigm of proteasome-related autoinflammation. Front Immunol 8:927

60. Garg A, Hernandez MD, Sousa AB, Subramanyam L, Martinez de Villarreal L, dos Santos HG, Barboza O (2010) An autosomal recessive syndrome of joint contractures, muscular atrophy, microcytic anemia, and panniculitis-associated lipodystrophy. J Clin Endocrinol Metab 95:E58-E63

61. Torrelo A, Patel S, Colmenero I, Gurbindo D, Lendinez F, Hernandez A, Lopez-Robledillo JC, Dadban A, Requena L, Paller AS (2010) Chronic atypical neutrophilic dermatosis with 
lipodystrophy and elevated temperature (CANDLE) syndrome. $\mathrm{J}$ Am Acad Dermatol 62:489-495

62. Finkelstein JL, Gala P, Rochford R, Glesby MJ, Mehta S (2015) HIV/AIDS and lipodystrophy: implications for clinical management in resource-limited settings. J Int AIDS Soc 18:19033

63. Akinci B, Koseoglu FD, Onay H, Yavuz S, Altay C, Simsir IY, Ozisik S, Demir L, Korkut M, Yilmaz N, Ozen S, Akinci G, Atik T, Calan M, Secil M, Comlekci A, Demir T (2015) Acquired partial lipodystrophy is associated with increased risk for developing metabolic abnormalities. Metabolism 64:1086-1095

64. Adachi M, Asakura Y, Muroya K, Goto H, Kigasawa H (2013) Abnormal adipose tissue distribution with unfavorable metabolic profile in five children following hematopoietic stem cell transplantation: a new etiology for acquired partial lipodystrophy. Clin Pediatr Endocrinol 22:53-64

65. Adachi M, Oto Y, Muroya K, Hanakawa J, Asakura Y, Goto H (2017) Partial lipodystrophy in patients who have undergone hematopoietic stem cell transplantation during childhood: an institutional cross-sectional survey. Clin Pediatr Endocrinol 26:99-108

66. Ceccarini G, Ferrari F, Santini F (2017) Acquired partial lipodystrophy after bone marrow transplant during childhood: a novel syndrome to be added to the disease classification list. J Endocrinol Invest 40:1273-1274

67. Bjornstad PG, Foerster A, Ihlen H (1996) Cardiac findings in generalized lipodystrophy. Acta Paediatr Suppl 413:39-43

68. Lupsa BC, Sachdev V, Lungu AO, Rosing DR, Gorden P (2010) Cardiomyopathy in congenital and acquired generalized lipodystrophy: a clinical assessment. Medicine (Baltimore) 89:245-250

69. (2015) Myalept (metreleptin) for injection: US prescribing information. Aegerion Pharmaceuticals Inc., Cambridge

70. Meehan CA, Cochran E, Kassai A, Brown RJ, Gorden P (2016) Metreleptin for injection to treat the complications of leptin deficiency in patients with congenital or acquired generalized lipodystrophy. Expert Rev Clin Pharmacol 9:59-68

71. Chan JL, Lutz K, Cochran E, Huang W, Peters Y, Weyer C, Gorden P (2011) Clinical effects of long-term metreleptin treatment in patients with lipodystrophy. Endocr Pract 17:922-932
72. Chong AY, Lupsa BC, Cochran EK, Gorden P (2010) Efficacy of leptin therapy in the different forms of human lipodystrophy. Diabetologia 53:27-35

73. Javor ED, Cochran EK, Musso C, Young JR, Depaoli AM, Gorden $\mathrm{P}$ (2005) Long-term efficacy of leptin replacement in patients with generalized lipodystrophy. Diabetes 54:1994-2002

74. Oral EA, Simha V, Ruiz E, Andewelt A, Premkumar A, Snell P, Wagner AJ, DePaoli AM, Reitman ML, Taylor SI, Gorden P, Garg A (2002) Leptin-replacement therapy for lipodystrophy. N Engl J Med 346:570-578

75. Javor ED, Ghany MG, Cochran EK, Oral EA, DePaoli AM, Premkumar A, Kleiner DE, Gorden P (2005) Leptin reverses nonalcoholic steatohepatitis in patients with severe lipodystrophy. Hepatology 41:753-760

76. Safar Zadeh E, Lungu AO, Cochran EK, Brown RJ, Ghany MG, Heller T, Kleiner DE, Gorden P (2013) The liver diseases of lipodystrophy: the long-term effect of leptin treatment. J Hepatol 59:131-137

77. Schlogl H, Muller K, Horstmann A, Miehle K, Puschel J, Villringer A, Pleger B, Stumvoll M, Fasshauer M (2016) Leptin substitution in patients with lipodystrophy: neural correlates for long-term success in the normalization of eating behavior. Diabetes 65:2179-2186

78. Simha V, Subramanyam L, Szczepaniak L, Quittner C, AdamsHuet B, Snell P, Garg A (2012) Comparison of efficacy and safety of leptin replacement therapy in moderately and severely hypoleptinemic patients with familial partial lipodystrophy of the Dunnigan variety. J Clin Endocrinol Metab 97:785-792

79. Ajluni N, Dar M, Xu J, Neidert AH, Oral EA (2016) Efficacy and safety of metreleptin in patients with partial lipodystrophy: lessons from an expanded access program. J Diabetes Metab 7:659

80. Brown RJ, Meehan CA, Cochran E, Rother KI, Kleiner DE, Walter M, Gorden P (2017) Effects of metreleptin in pediatric patients with lipodystrophy. J Clin Endocrinol Metab 102:1511-1519

81. Brown RJ, Chan JL, Jaffe ES, Cochran E, DePaoli AM, Gautier JF, Goujard C, Vigouroux C, Gorden P (2016) Lymphoma in acquired generalized lipodystrophy. Leuk Lymphoma 57:45-50 